\title{
PATHOLOGICAL FRACTURE OF LUMBAR VERTEBRA IN CHILDREN WITH ACUTE NEUROLOGICAL DEFICIT: CASE REPORT
}

Adalberto Bortoletto', Luiz Cláudio Lacerda Rodrigues², Marcelo Hide Matsumoto³

\begin{abstract}
This study reports on a case of lymphoma in a 13-year-old patient who came to a consultation with lumbar pain. The patient had suffered low-intensity trauma in the lumbar region that resulted in persistent pain of progressive nature. In an emergency evaluation, radiographic examination showed a spinal fracture. The patient was then sent to the specialist outpatient clinic of the same hospital. The initial examinations confirmed the diagnosis of a pathological fracture surrounded by a tissue mass, thus indicating the presence of a tumor. Subsequently, the patient evolved with lower-limb paresthesia and urine retention, without any pathological diagnosis for the lesion. The patient then underwent emergency surgery to achieve stabilization and neurological decompression, and material from the lesion
\end{abstract}

was sent for anatomopathological examination. The result from the anatomopathological examination suggested that the lesion was a small-cell tumor, although leaving some doubt. Immunohistochemistry defined the diagnosis of lymphoma. The patient was then sent for oncological treatment. The aim of this study was to report on a rare case of lymphoma in a child with an initial diagnosis of a pathological fracture in the lumbar spine. It is important to investigate fractures associated with mild trauma in children. Precise diagnosis results in effective attendance with better results for these patients.

This patient underwent chemotherapy and achieved a good response, with positive repercussions for his prognosis.

Keywords - Spinal Fractures/diagnosis; Spine; Neoplasm Metastasis; Lymphoma/therapy

\section{INTRODUCTION}

Lumbar spine fractures are uncommon injuries in young or elderly adults. They generally result from medium to high-energy trauma. They most frequently affect adults and are mostly associated with falling from a height and with vehicle accidents. In children, lumbar spine fractures should be investigated carefully, and especially if the trauma does not explain the injury.

These fractures in children may be associated with a primary pathological condition, and this always needs to be ruled out. Tumor lesions are one of the causes that should be thought of and investigated by the attending physician.

Infiltrations in vertebral bodies due to lymphoproliferative diseases are not uncommon, but it is rare to make this diagnosis with the fracture presenting as the first symptom. When such infiltrations are found alone in the spine, they are called reticulum cell sarcomas, but only $5 \%$ of these lymphomas are solita$\mathrm{ry}^{(1)}$. This type of lesion in the spine responds well to radiotherapy, especially single lesions. Chemotherapy is reserved for diffuse cases. The factor that most

\footnotetext{
1 - Head of the Spinal Surgery Group, Orthopedics and Traumatology Service, Hospital Santa Marcelina, Itaquera, São Paulo, Brazil.

2 - Attending Physician in the Spinal Surgery Group, Orthopedics and Traumatology Service, Hospital Santa Marcelina, Itaquera, São Paulo, Brazil.

3 - Head of the Orthopedics and Traumatology Service, Hospital Santa Marcelina, Itaquera, São Paulo, Brazil.
}

Work performed at the Department of Orthopedics and Traumatology, Hospital Santa Marcelina, Itaquera, São Paulo, SP, Brazil.

Correspondence: Luiz Cláudio Lacerda Rodrigues - Rua Santa Marcelina 177, Itaquera - 08270-070 - São Paulo, SP (Setor Ortopedia e Traumatologia).

E-mail: luizclr@terra.com.br

Work received for publication: March 27, 2010; accepted for publication: June 14, 2010. 
influences the prognosis is the staging, and the response had been shown to be worse when the lesion affects bone tissue and adjacent soft tissues.

In the radiological condition compatible with this, a poorly defined area with bone destruction and permeative appearance is observed. Sometimes the cortical bone may be thickened due to a periosteal reaction ${ }^{(2)}$.

\section{MATERIAL AND METHOD}

The patient was a healthy 13-year-old male student. He had suffered a fall from his own height that had evolved with moderate-intensity lumbar pain. He required emergency care and was medicated with analgesics. One week later, with continuing pain, the patient returned for further attention. From radiographs, a diagnosis of wedge fracture of the L4 body with $70 \%$ height loss was made and the patient was referred to our service (Figure 1).

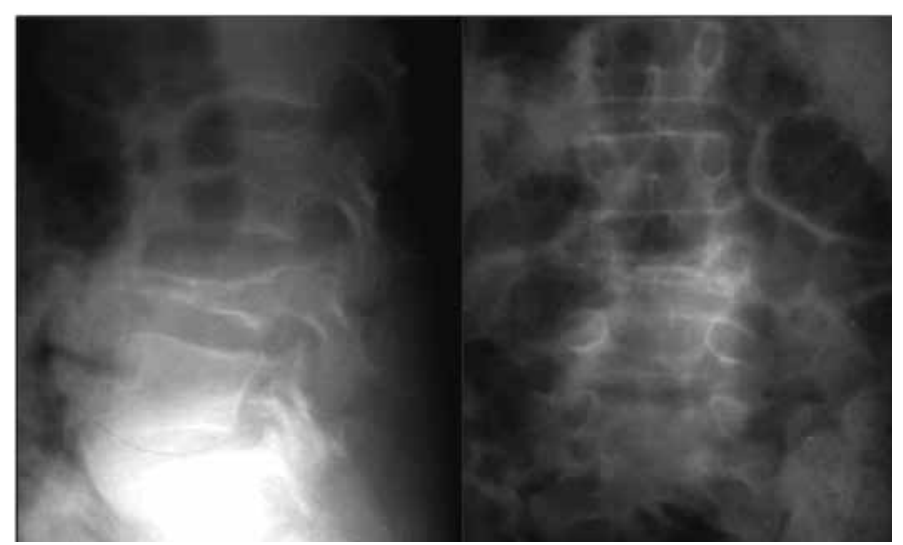

Figure 1 - Initial X-ray showing the fracture.

After anamnesis and physical examination, the patient underwent computed tomography. This showed a fracture vertebral body associated with lytic lesions and involvement of soft tissues. At this time, a magnetic resonance examination was requested (Figure 2), and this showed an anterior and posterior mass affected the entire vertebral body, adjacent soft tissues and vertebral canal. Two weeks after the examination, the patient presented paresthesia in the lower limbs and underwent surgery with posterior instrumentation and decompression, and material was collected for anatomical examination (Figure 3).

The initial diagnostic hypotheses were Ewing's sarcoma and lymphoma, and the final diagnosis was given by immunohistochemistry.

Rev Bras Ortop. 2011;46(3):315-17

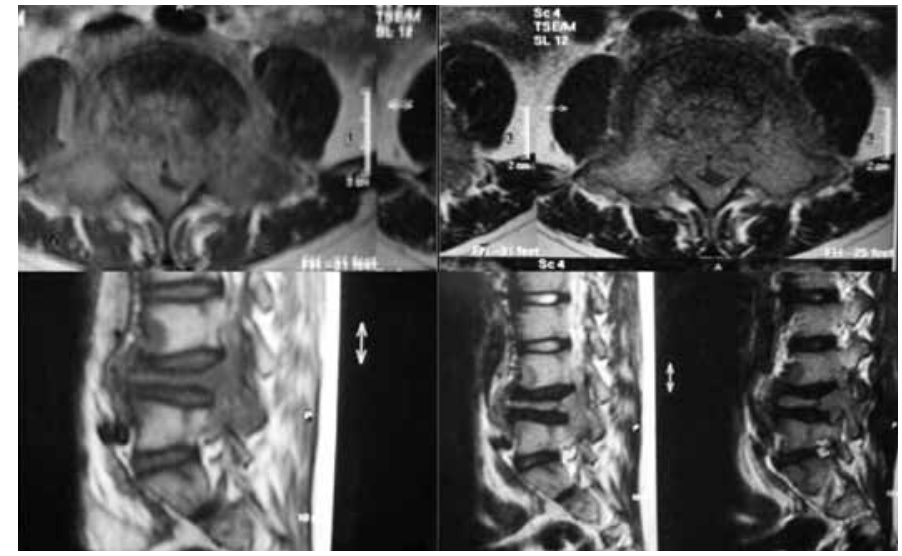

Figure 2 - Magnetic resonance imaging showing the mass and the pathological fracture in sagittal slices.

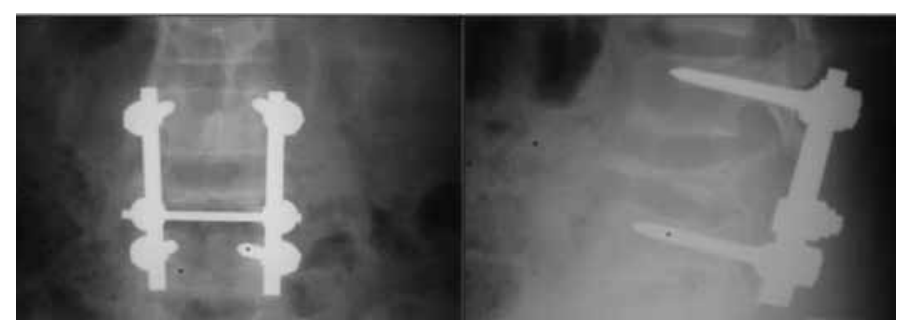

Figure 3 - Postoperative appearance with stabilization and decompression.

The patient was referred to the oncology sector, where he underwent radiotherapy and chemotherapy, which produced an improvement in his clinical condition and remission of the neurological and pain symptoms. Staging was performed, in which no other disease sites were observed.

\section{RESULTS}

The patient presented good postoperative evolution, with improvement of the pain, remission of the neurological condition and stabilization of the fracture. He is currently medicated with adjuvant chemotherapy.

\section{DISCUSSION}

Several authors have questioned the origin of primary lymphoma of the spine. In Rubestein's study, it was believed that this condition might have its origins in the epidural lymphoid tissue or in lymph nodes for vertebrae, thus explaining the involvement of soft tissues ${ }^{(2)}$.

Lymphomas are more common in men than in women, with proportions of 1.6:1 $1^{(2,3)}$. Lymphoma causing radicular compression or medullary compression is rare $^{(3)}$. The diagnosis of bone lymphoma is generally secondary in patients who present the disease in 
other localities. Primary diagnoses in the musculoskeletal system are $\operatorname{rare}^{(3)}$, with an incidence of less than $10 \%$. When this occurs, it most commonly involves small bones such as the ileum, scapula and vertebrae, while among the tubular bones it is located in the femur and tibia. In the vertebrae, the incidence is $1.7 \%{ }^{(3)}$, while diffuse involvement is rare.

In cases affecting the spine, the initial symptom is lumbalgia, with or without accompanying sciatica. Acute neurological deficits may occur, and this was observed in our patient.

In the spine, the locations most affected are the thoracic region (69\% of the cases), lumbar region $(27 \%)$ and cervical region $(14 \%)^{(4)}$. According to some authors, this distribution is due to the greater number of thoracic vertebrae and their specific vascularization ${ }^{(5)}$.

The initial trio of symptoms includes weakness in the lower limbs, localized lumbar pain and urinary abnormalities ${ }^{(6)}$. Radiographic images may show destruction of the pedicle, fracturing with stenosis of the medullary canal and a soft-tissue mass; these are visible in 15 to $42 \%$ of the patients ${ }^{(7)}$. Computed tomography and magnetic resonance together provide an excellent assessment of the lesion and its real extent ${ }^{(8)}$.

Maheshwari et $\mathrm{al}^{(9)}$ reported the case of a patient with a diagnosis of Pott's disease, which was determined because of the radiological presentation of bone destruction and neoformation. This detail is important, because in a country like Brazil, in which tuberculosis is endemic, it cannot be forgotten that other diseases affect the spine, and that their radiological findings may often mimic tuberculosis.

In a study in 1976, Haddad and Thael ${ }^{(10)}$ already made a comparison between metastatic carcinoma-

\section{REFERENCES}

1. Sucu HK, Ciçek C, Rezanko T, Bezircioglu H, Ersahin Y, Tunakan M, et al. Percutaneous computed-tomography-guided biopsy of the spine: 229 procedures. Joint Bone Spine. 2006;73(5):532-7.

2. Ricchetti ET, Erol B, Stern J, Russo P, States L, Dormans JP. Lower back pain and mass in a 13-year-old girl. Clin Orthop Relat Res. 2005;(430):248-57.

3. Ebus SC, Bernsen HJ, Norel Van GJ, Donk R. Primary non-Hodgkin's lymphoma in multiple vertebrae presenting as a lumbar radicular syndrome: A case report. Spine (Phila Pa 1976). 2002;27(10):E271-3.

4. Kapoor R, Kumar V, Shrama SC. Primary extradural Non-Hodging's lymphoma. JK Science. 2006;8(1):45-8.

5. Devita VT, Jaffe ES. Hodgikins's disease and non-hodgkinins's lymphoma. In: Devita VT, Theodore S. Lawrence TS, Jaffe ES, Hellmin S, Rosenberg RA et al. Cancer principles and practice of oncology. Philadelphia: Lippincolt; 2005. p. 2085-220.

6. Mullins GM, Flynn JP, el-Mahdi AM, McQueen JD, Owens AH Jr. Malignant lymphoma of the spinal epidural space. Ann Intern Med. 1971;74(3):416-23. tous tumors and lymphomas and observed that the latter presented better prognosis when associated with the disease. Patients presented neurological compression that improved after decompression and stabilization, but it was already seen that controlled studies would be needed.

We agree with the study by Jesus-Garcia Filho and Puertas ${ }^{(11)}$, in which it was reported that patients with neurological deficits should undergo emergency decompression. This was what was done in our patient's case, given that when he underwent surgery, no biopsy had yet been performed.

Delfino et al ${ }^{(12)}$ reported difficulty in assessing spinal tumors and hence difficulty in assessing such patients. We also found this, since we saw from the literature that most studies relating to specific tumor were case reports or samples of small groups. Studies on larger numbers of patients presented heterogenous groups that were all assessed together. However, we agree that surgical treatment has its place, both as curative treatment in specific cases and as palliative treatment for improving patients with limited prognoses. This was well documented by Tokuhashi ${ }^{(13)}$.

\section{CONCLUSION}

Young patients with spinal fractures caused by mild trauma with or without an associated history of trauma should be carefully evaluated so that diagnoses of secondary lesions are not missed, considering that at this age, such lesions develop rapidly with devastating action. Our patient evolved well after surgery and adjuvant therapy and presents a normal life today, although he is still undergoing disease remission control.

7. Friedman M, Kim TH, Panahon AM. Spinal cord compression in malignant lymphoma. Treatment and results. Cancer. 1976;37(3):1485-91.

8. Bragg DG, Cosby TV. Ward JH. New concepts in the non-Hodgkin lymphomas: radiologic implications. Radiology. 1986;159(2):291-304.

9. Maheshwari V, Alam K, Khan SA, Mehdi G, Iraqi AA. Lymphoma of spine presenting as Pott's desease:A case report. Ind J Tub. 2000;47:107-8.

10. Haddad P, Thaell JF, Kiely JM, Harrison EG, Miller RH. Lymphoma of the spinal extradural space. Cancer. $1976 ; 38(4): 1862-6$.

11. Jesus-Garcia Filho R, Puertas EB, Oliveira CE, Chagas JC, Korukian M Resultado do tratamento das lesões metastáticas na coluna vertebral. Rev Bras Ortop. 1993;28(11/12):803-8.

12. Delfino HAL, Rodriguez Fuentes AE, Vianna LL.Tratamento cirúrgico dos tumores da coluna vertebral. Rev Bras Ortop.1996;31(2):111-8.

13. Tokuhashi $Y$, Matsuzaki H, Toriyama S, Kawano H, Ohsaka S. Scoring system for the preoperative evaluation of metastatic spine tumor prognosis. Spine (Phila Pa 1976). 1990;15(11):1110-3. 